\title{
Design of Power Pool Scheme for Demand-Side Management of Co-Located Banks
}

\section{Ernest Ozoemela Ezugwu*, Damian Obioma Dike, Samuel Okechukwu Okozi, Matthew Olubiwe, Chiedozie Francis Paulinus-Nwammuo}

Department of Electrical and Electronic Engineering, Federal University of Technology, Owerri, Nigeria

Email address:

ernest.ezugwu@futo.edu.ng (E. O. Ezugwu),ezutek@gmail.com (E. O. Ezugwu)

${ }^{*}$ Corresponding author

\section{To cite this article:}

Ernest Ozoemela Ezugwu, Damian Obioma Dike, Samuel Okechukwu Okozi, Matthew Olubiwe, Chiedozie Francis Paulinus-Nwammuo. Design of Power Pool Scheme for Demand-Side Management of Co-Located Banks. American Journal of Electrical Power and Energy Systems. Vol. 8, No. 4, 2019, pp. 86-94. doi: 10.11648/j.epes.20190804.11

Received: June 12, 2019; Accepted: July 12, 2019; Published: July 26, 2019

\begin{abstract}
The design of a power pool scheme for demand-side management of co-located banks in Owerri metropolis, Nigeria has been carried out in this work. The paper addressed the problem of matching instantaneous load demand with appropriate generator capacities which results from dynamic nature of small and medium scale industrial load, such as co-located banks. It also aimed at proffering solutions to health and environmental problems associated with use of scattered single generators per firm. A model for interconnection of generators and loads in a pool structure was developed to form a ring network, analogous to a typical power system. One of the generators in the pool was chosen as the slack bus and the other generators and load buses were arranged in the power pool arrangement such that Newton-Raphson's method could be applied in load flow analysis. With this modeling and application of appropriate schedule, a cooperative pooling model was developed such that only the exact generating capacities were deployed. The proposed model was simulated by paralleling three 200kVA generator units in a synchronized ring network to serve the entire five banks. Results from the load flow analysis showed that the per unit voltage magnitudes at buses 1, 2, 3, 4 and 5 were 1.000, 0.997, 1.000, 0.998 and 1.000 respectively, while voltage mismatch angles (degree) were also gotten as $0.000,0.003,0.024,0.060$ and 0.086 respectively for the buses 1 to 5 . From the cost benefit analysis carried out, the benefit-cost ratio (BCR) of 1.965 was calculated, which showed that this project will be very beneficial to the co-operating banks. Scheduling the operations of the three generators using mathematical permutation and combination model showed that the total man-hour of the plant operators is reduced by $40 \%$. Also, applying the greenhouse gases emissions cost model it was found that the carbon footprints i.e. greenhouse cost for the interconnected network is reduced by $40 \%$.
\end{abstract}

Keywords: Power-pool, Demand-side Management, Generator Scheduling, Instantaneous Load Matching, Electricity Consumer Cooperative

\section{Introduction}

The growth in technology and economy of any nation is highly dependent on her energy generation, transmission and distribution [1]. Electricity occupies a top position in the energy hierarchy; and just like every other vital commodity, should be subject to efficient management. In these days of deregulated electricity market in Nigeria, much attention has been paid to management and optimization of power generated and power consumed on the demand-side within the interconnected grid system [2]. This is because, to practically meet all the energy demand from the end users, the grid system must be designed such that it should satisfy the peak power demand at all times [3]; which is presently not realizable in this part of the world due to imbalance in energy demand and supply.

Presently, the Nigerian power sector is marked with low generating capacity compared to the demand capacity. Recently, the Transmission Company of Nigeria (TCN) reported the drop in power generation from 3,959 megawatts on January 4, 2017 to 2,662 megawatts on January 22, 2017 [4], while the present estimated consumption capacity is over 30,000 megawatts. This has denied Nigerian citizen access to 
uninterrupted power supply. The power sector in Nigeria has been seen by many analysts as the key constraints on economic development. In 2015 World Bank ranked Nigeria 170 of 189 in the world, with a distance to frontier (DTF) or ease of doing business (EDB) score of $47.33 \%$, against Singapore's $88.27 \%$ and Eritrea's $33.16 \%$ [5].

However in the 2016 version of the report, Nigeria climbed one step to 169 th position, but sheds about $3 \%$ point to clock $44.69 \%$ [6]. It was clearly highlighted in the report that Nigeria's major problem in doing businesses is poor access to electricity. Most of the time, when even connected to the electricity providers, Nigeria business most reported problem is the dwindling power supply. About $83 \%$ of all manager surveyed considered electricity outage to be a serious problem - more than any other business constraint [5]. Firms of all sizes, in all the states and sectors in Nigeria reported average power outages equivalent to eight hours per day [5].

Due to the dwindling nature of the public utilities, many companies had resolved in providing their own power using private diesel generator sets which are more reliable but has high running cost, thus, leading to high costs of their products and services [7-8]. Major cities in Nigeria are planned in such a way that some regions are mapped out for particular business. Examples of such could be found at Bank road Owerri and Okpara avenue Enugu both in South Eastern Nigeria, where different banks are co-located. These banks like many other industries rely heavily on their private generators as alternative source of power supply and have same energy consumption pattern; hence good candidate for this work.

In most cases, their generators are over-rated and underutilized, creating energy waste and environmental pollution. So, this paper presents an improved and environment friendly scheme whereby the banks' individual diesel generators may be integrated into a power pool system, perform demand-based generator scheduling and dispatch generated power to co-operating banks, and these will culminate to the "design of a power pool scheme for demand side management of co-located banks".

\section{Literature Review}

Many previous related literatures were reviewed which helped in carrying out the main objective of this paper design of a power pool scheme for demand side management of co-located banks.

Definition of terms:

Demand-side management (DSM) - This is a proactive approach of demand management mechanisms aimed at making the electricity consumers' energy-demand efficient in the long-term. Demand-side management also describes various measures that can be taken on the customer side for energy efficiency or conservation purposes $[2,9]$. Designing of power pooling scheme falls under this method of demand management mechanisms. In the literature, demand-response and demand-side management terms are often used as synonymous [10-11].

Power-pooling - Power pool arrangements have mostly evolved from simple interconnections of closely located consumers' diesel generators to interconnections between neighboring utilities [12], so as to support each other in the case of emergencies [13]. It has also grown into more sophisticated formal legal entities whereby countries team up with other countries around it to form an electricity cooperative scheme. An example of this arrangement is the West African Power Pool (WAPP). WAPP was set up in 1999 by the ECOWAS Heads of States and Government by Decision A/DEC.5/12/99 [14].

Generator synchronization -This is the process of matching a source (generator) with an existing power system, making it possible to operate these systems in parallel [15].

During this process the voltage, the frequency, and the phase angle of the new generator is synchronized with the voltage, frequency and phase angle of the existing generators [15].

The two or more generators must have almost identical voltage magnitude, frequency and phase angle relationship in order to safely parallel the systems [16]. When paralleled, the synchronized power system can exchange power and load flows.

Certain conditions must be met to reach synchronization, for two or more generators to be connected together with no harm to the system and to the connected loads; the following electrical quantities of the Generators must match [16]:

i Phase sequence

ii Voltage amplitude

iii Frequency

iv Phase angle

\section{System Design}

These are the algorithm/workflow used in achieving system design for the power pool scheme:

i Collection of the participant data; which comprises of the load data, generator data and other criteria data like co-location position.

ii Develop an interconnected circuit network for the selected banks

iii Carry out load flow analysis on the interconnected network

iv Schedule generators for operation

$\mathrm{v}$ Synchronize the generators in operation

vi Supply the demanded loads

System Flowchart

\subsection{Load Data}

Tables 1 contains the total connected loads of the various participating banks. The loads were gotten from the labeled power consumption capacities from of each of the connected electrical appliances in Watts. 
Table 1. Load data for the co-located banks.

\begin{tabular}{ll}
\hline Banks & Connected electrical loads (Watts) \\
\hline Bank A & $95841 \mathrm{~W}$ \\
Bank B & $92350 \mathrm{~W}$ \\
Bank C & $92346 \mathrm{~W}$ \\
Bank D & $86492 \mathrm{~W}$ \\
Bank E & $98628 \mathrm{~W}$ \\
\hline
\end{tabular}

From the load data in Table 1 the total connected load by the co-located banks can be calculated thus:

Total Connected Load $=(95841+92350+$ $92346+86492+98628)=465657 \mathrm{~W}$

Table 2 is the load profile of the selected banks A to E; it shows how the loads vary at different hours of the day. From the load profile Table 2, the maximum demand occurs between the hours of 12 noon to 16.00 hours, therefore the maximum demand is $=76672+73880+73880+69192+78904$ $=372528 \mathrm{~W}$

Table 2. Hourly Load profile of Banks A to E.

\begin{tabular}{|c|c|c|c|c|c|}
\hline Hours of the day & Load For Bank A (W) & Load For Bank B (W) & Load For Bank C (W) & Load For Bank D (W) & Load For Bank E (W) \\
\hline 0 & 9584 & 9235 & 9235 & 8649 & 9863 \\
\hline 1 & 9584 & 9235 & 9235 & 8649 & 9863 \\
\hline 2 & 9584 & 9235 & 9235 & 8649 & 9863 \\
\hline 3 & 9584 & 9235 & 9235 & 8649 & 9863 \\
\hline 4 & 9584 & 9235 & 9235 & 8649 & 9863 \\
\hline 5 & 9584 & 9235 & 9235 & 8649 & 9863 \\
\hline 6 & 9584 & 9235 & 9235 & 8649 & 9863 \\
\hline 7 & 57504 & 55410 & 55410 & 51894 & 59178 \\
\hline 8 & 57504 & 55410 & 55410 & 51894 & 59178 \\
\hline 9 & 57504 & 55410 & 55410 & 51894 & 59178 \\
\hline 10 & 57504 & 55410 & 55410 & 51894 & 59178 \\
\hline 11 & 57504 & 55410 & 55410 & 51894 & 59178 \\
\hline 12 & 76672 & 73880 & 73880 & 69192 & 78904 \\
\hline 13 & 76672 & 73880 & 73880 & 69192 & 78904 \\
\hline 14 & 76672 & 73880 & 73880 & 69192 & 78904 \\
\hline 15 & 76672 & 73880 & 73880 & 69192 & 78904 \\
\hline 16 & 76672 & 73880 & 73880 & 69192 & 78904 \\
\hline 17 & 76672 & 73880 & 73880 & 69192 & 78904 \\
\hline 18 & 9584 & 9235 & 9235 & 8649 & 9863 \\
\hline 19 & 9584 & 9235 & 9235 & 8649 & 9863 \\
\hline 20 & 9584 & 9235 & 9235 & 8649 & 9863 \\
\hline 21 & 9584 & 9235 & 9235 & 8649 & 9863 \\
\hline 22 & 9584 & 9235 & 9235 & 8649 & 9863 \\
\hline 23 & 9584 & 9235 & 9235 & 8649 & 9863 \\
\hline
\end{tabular}

\subsection{Interconnected Circuit Network for the Selected Banks}

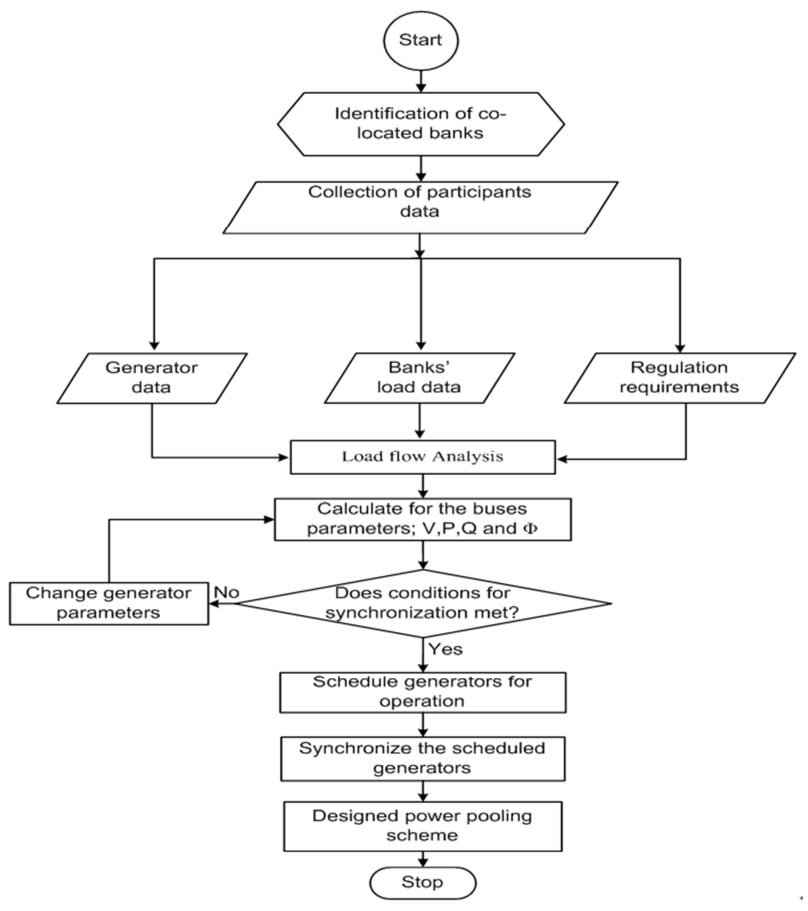

Figure 1. Flow chart for the design of power pooling scheme for co-located bank. 
A measuring tape was used to measure the distance between the selected banks so as to get the equivalent lengths of the interconnecting cables. Figure 1 has the detail of the measurement and the impedance along the lines.

Two pegs were used in this measurement, one peg was placed at the plant house of bank A to mark the beginning and another peg at the plant house of bank $\mathrm{C}$ and the distance between bank $\mathrm{A}$ and bank $\mathrm{C}$ was measured, the same process was repeated for measuring the distances between banks, $C B$, $\mathrm{BD}, \mathrm{DE}$ and EA as recorded in Table 8. The plant houses of banks A, B, C, D and E represent the position of the buses.

Table 3. Calculated line impedances for the co-located bank network.

\begin{tabular}{llll}
\hline Banks & Distance apart $(\mathbf{k m})$ & Impedance calculation & Total impedance $(\mathbf{\Omega} / \mathbf{k m})$ \\
\hline B to C & 0.06 & $(0.0966+\mathrm{j} 0.0752) \times 0.06$ & $0.005796+\mathrm{j} 0.004512$ \\
B to D & 0.15 & $(0.0966+\mathrm{j} 0.0752) \times 0.15$ & $0.01449+\mathrm{j} 0.01128$ \\
C to A & 0.17 & $(0.0966+\mathrm{j} 0.0752) \times 0.17$ & $0.016422+\mathrm{j} 0.012784$ \\
E to A & 0.04 & $(0.0966+\mathrm{j} 0.0752) \times 0.04$ & $0.003864+\mathrm{j} 0.003008$ \\
D to E & 0.05 & $(0.0966+\mathrm{j} 0.0752) \times 0.05$ & $0.00483+\mathrm{j} 0.00376$ \\
\hline
\end{tabular}

Figure 2 is the developed ring circuit network for the co-located banks. The three generators tied to buses 1, 5 and 3 are selected based on the calculated total load demand of the banks.

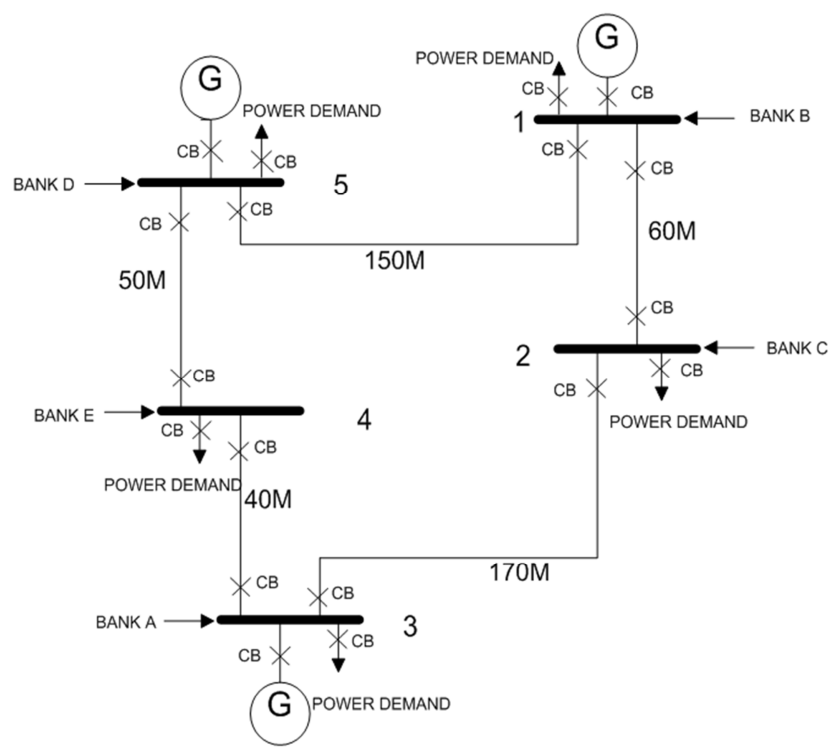

Figure 2. Interconnected ring circuit for the co-located banks.

\subsection{Cable Sizing}

The total connected load has been calculated as $474.44 \mathrm{~kW}$, therefore, applying the general power equation we can calculate for the total current drawn from the network.

Thus:

$$
P=\sqrt{3} I V \cos \theta
$$

Where $\mathrm{P}=465657 \mathrm{~W}, \mathrm{~V}=415 \mathrm{~V}$ and $\cos \theta=0.8$

$465657=\sqrt{3} \times I \times 415 \times 0.8$

$\mathrm{I}=809.78 \mathrm{~A}$ (this is the line to line current)

$$
\frac{\text { current }(I)}{\text { phase }}=\frac{809.78}{\sqrt{3}}=467.53 \mathrm{~A}
$$

From the calculated current value of $467.53 \mathrm{~A}, 240 \mathrm{~mm}^{2}$ three core copper cable was chosen from the cable size chart sheet for the interconnection of the co-located banks.
The load flow network is depicted in Figure 3. The total connected load for the bank network is $465.657 \mathrm{~kW}$. From the total connected load calculated it is noticed that three generator units of $160 \mathrm{~kW}$ capacity each are capable of supplying the entire five banks' load of $(465.657 \mathrm{~kW})$. Thus, this formed the basics of the load flow analysis in this work.

With the calculated impedances in Table 3 , and load data in Table 1 the buses interconnections can be drawn to form a ring network as shown in Figure 3, which will be used for the load flow analysis. From the result of the load flow, it will be ascertained whether the system is feasible or not.

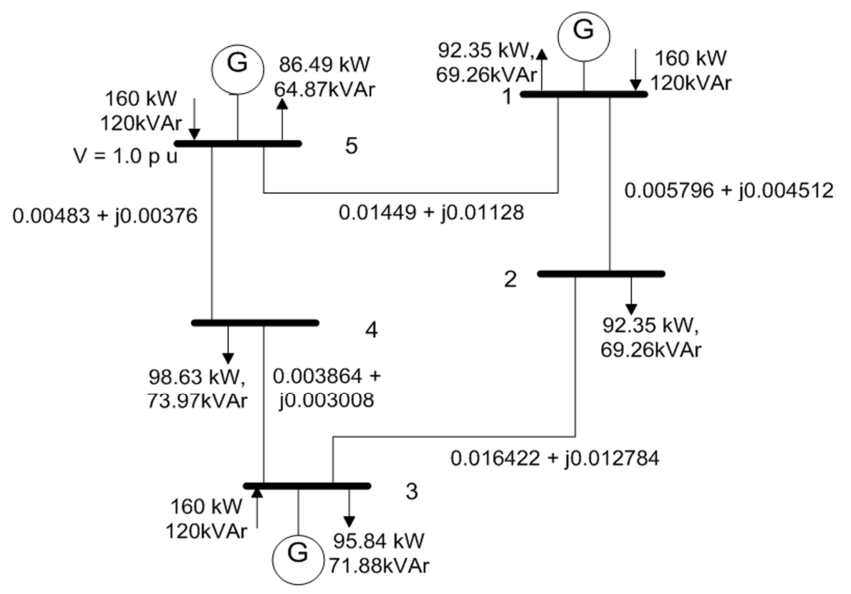

Figure 3. Load flow network for the interconnected banks.

\subsection{Generator Scheduling}

The power ratings of the participating banks' generators are same, with each rated as $200 \mathrm{kVA}$. From the load data tables, the total load demand is calculated to be $474.44 \mathrm{~kW}$, therefore, with the information above, three generators of $200 \mathrm{kVA}$ each at power factor of 0.8 can comfortably serve the peak load of $474.44 \mathrm{~kW}$, for the entire co-located bank network, thus:

$$
\text { Power in Watts }=\text { Power in VA } \times \text { Power factor }
$$

For the $200 \mathrm{kVA}$ generator $\mathrm{kW}=200 \times 0.8=160 \mathrm{~kW}$

$$
\text { The total load demand from the network }
$$$$
=372.528 \mathrm{~kW}
$$

Assuming that no new load is introduced into the system, therefore to instantaneously match the total connected load 
three generators of $160 \mathrm{~kW}$ can be scheduled to serve the load each day.

$3 \times 160 \mathrm{~kW}=480 \mathrm{~kW}$. Scheduling these three generators, there will be allowance of $480-372.528=87.472 \mathrm{~kW}$ for emergency loads.

The scheduling of these selected three generators from five different commercial banks can be done using mathematical permutation and combination model as shown in equation (3).

The number of different combinations of $m$ objects out of $n$ is denoted by:

$$
{ }^{\mathrm{n}} C_{m} \equiv\left(\begin{array}{c}
n \\
m
\end{array}\right)=\frac{n !}{m !(n-m) !}=\frac{n \times(n-1) \times \ldots \times(n-m+1)}{m \times(m-1) \ldots \times 1}
$$

Using equation (3), the numbers of ways these three generators can be selected and combined from different banks is given bellow.

$$
5 C_{3}=\left(\begin{array}{l}
5 \\
3
\end{array}\right)=\frac{5 !}{3 ! \times 2 !}=\frac{120}{6 \times 2}=10 \text { ways }
$$

Let each of these three generators be represented by the first initial of the bank it comes from as shown in Table 4.

Table 4. Scheduled generator notations and capacity.

\begin{tabular}{lll}
\hline Banks' generators & $\begin{array}{l}\text { Size of generator } \\
\text { (kVA) }\end{array}$ & $\begin{array}{l}\text { Generator maximum } \\
\text { capacity (kW) }\end{array}$ \\
\hline Bank A & 200 & 160 \\
Bank B & 200 & 160 \\
Bank C & 200 & 160 \\
Bank D & 200 & 160 \\
Bank E & 200 & 160 \\
\hline
\end{tabular}

From the Table 4 these three generators are arranged as in the Table 5 and Table 6 to serve the entire banks for the scheduled numbers of business days.

Table 5. Scheduled generators for the first week.

\begin{tabular}{lll}
\hline $\begin{array}{l}\text { Generators in } \\
\text { operation }\end{array}$ & First week & $\begin{array}{l}\text { Banks to supply } \\
\text { power }\end{array}$ \\
\hline DCB & Monday & Banks D, C and B \\
DCE & Tuesday & Banks D, C and E \\
DCA & Wednesday & Banks D, C and A \\
DBE & Thursday & Banks D, B and E \\
DBA & Friday & Banks D, B and A \\
\hline
\end{tabular}

Table 6. Scheduled generators for the second week.

\begin{tabular}{lll}
\hline $\begin{array}{l}\text { Generators in } \\
\text { operation }\end{array}$ & Second week & $\begin{array}{l}\text { Banks to supply } \\
\text { power }\end{array}$ \\
\hline DEA & Monday & Banks D, E and A \\
CBE & Tuesday & Banks C, B and E \\
CBA & Wednesday & Banks C, B and A \\
CEA & Thursday & Banks C, E and A \\
BED & Friday & Banks B, E and D \\
\hline
\end{tabular}

\subsection{Generator Synchronization}

From the literature and practice, there are certain conditions that must be met before two or more generators can be synchronized.

The tolerance window should fall within the acceptable tolerance range of [16]:

i Voltage angle, \pm 10 degrees ii Voltage magnitude, 0 to +5 percent.

iii Frequency $\pm 0.067 \mathrm{~Hz}$

This method of synchronization proposed for this design is the synchroscope method, which has similarity with the two bright and one dark lamp method and indicates plainly, when the generator frequency is higher or lower than the bus bar frequency. This method is used for better accuracy of parameters before generator paralleling [17]. It has two pair terminals wherein one of the pairs of terminals is marked "existing" and the other "incoming". The existing pair are connected to the bus bar with the already running generators and other pair are to be connected to the terminals of incoming generator. The synchroscope compares the voltage profile of the existing bus with the voltage profile of the incoming generator to check if it meets the requirements for paralleling.

After the voltage condition is checked and confirmed, the plant operator has to check the synchroscope dial. The rate with which the pointer rotates indicates the difference in frequency between the incoming alternator and the bus bar [17]. Moreover, the direction to which the pointer rotates; either fast or slow tells whether the incoming generator frequency is higher or lower than the bus bar frequency and hence the pointer moves either fast or slow [16]. The appropriate correction has to be made to control the speed of the alternator so as to bring the rate of rotation of pointer as small as possible. Therefore, synchroscope along with voltmeters are enough for synchronization process. However, in most of the cases a set of lights along with synchroscope is used as a double-check system.

The process of generators paralleling must be done carefully to prevent the disturbances in the system as well as to avoid a serious damage to the generators. Three lamps method is not preferred today due to less accuracy and manual operation.

The synchroscope synchronizing panel is as depicted in Figure 4.

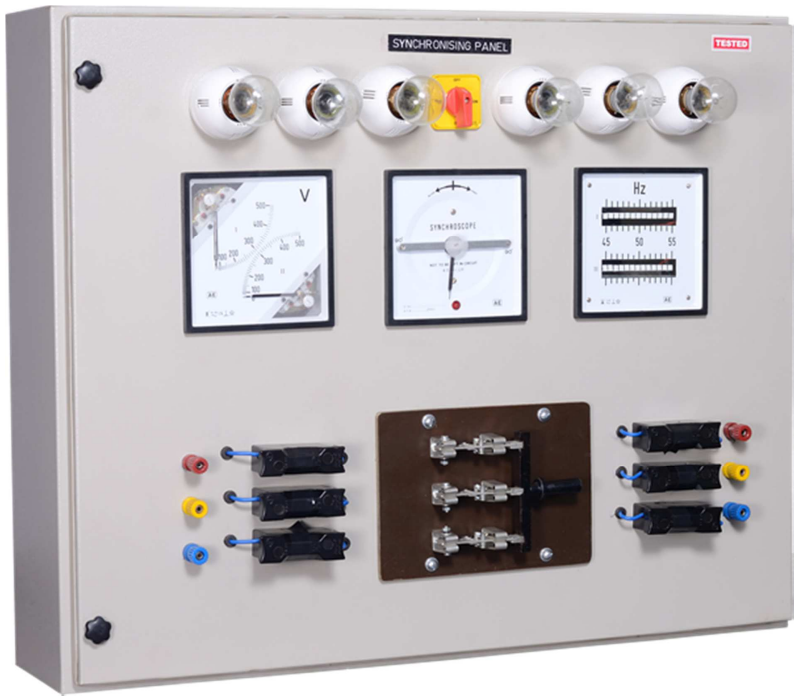

Figure 4. Synchroscope Synchronizing Panel [18]. 


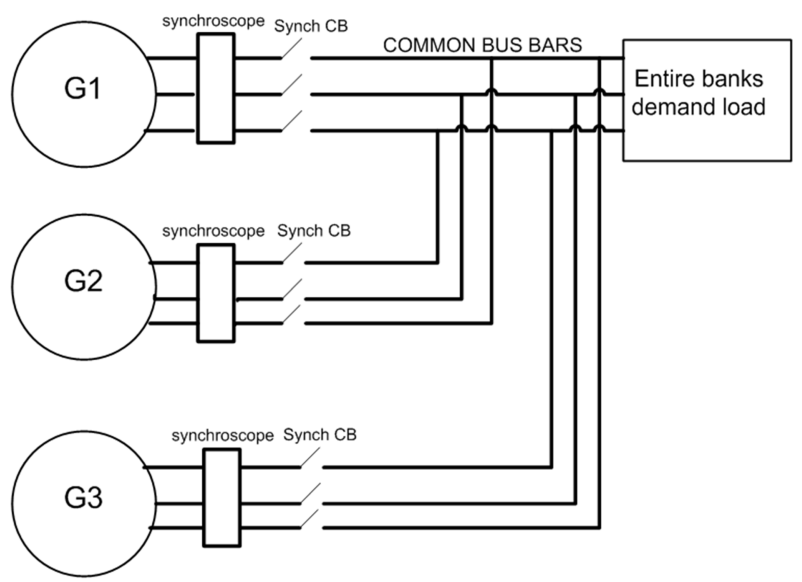

Figure 5. Three scheduled generators synchronized.

\section{Cost Benefit Analysis of the Designed Power Pooling Scheme}

Cost benefit analysis is a systematic approach of estimating the project investment; it is used to determine the best option that will achieve the highest benefit while preserving costs. In cost benefit analysis, the project with benefit-cost ratio (BCR) above 1 is selected.

The dynamic model of the total fuel consumed by diesel generator over a period of time $(\mathrm{t})$ is given by the following equations [19].

Generatorat $1 / 4$ Load;

$$
\mathrm{Y}_{0.25}=9.2 \times 10^{-6} \mathrm{x}^{3}-0.0011 \mathrm{x}^{2}+0.098 \mathrm{x}-0.88
$$

Generatorat $1 / 2$ Load;

$$
\begin{gathered}
\mathrm{Y}_{0.5}=9.2 \times 10^{-6} \mathrm{x}^{3}-0.0019 \mathrm{x}^{2} 0.16 \mathrm{x}-1.5 \\
\text { Generatorat } 3 / 4 \text { Load; } \\
\mathrm{Y}_{0.75}=1.4 \times 10^{-5} \mathrm{x}^{3}-0.0029 \mathrm{x}^{2}+0.22 \mathrm{x}-2 \\
\text { Fulload } ; \\
\mathrm{Y}_{1}=1.2 \times 10^{-5} \mathrm{x}^{3}-0.0025 \mathrm{x}^{2}+0.23 \mathrm{x}-2
\end{gathered}
$$

Where $\mathrm{Y}$ is the gallons of fuel needed per hour for load $\mathrm{X}$ at different loadings.

From the Equations (4) to (7), the following approximate fuel consumptions were calculated for different rating of generators as shown in Table 7.

Table 7. Approximate Fuel Consumption Chart for diesel generators.

\begin{tabular}{lllll}
\hline $\begin{array}{l}\text { Generator } \\
\text { Size }(\mathbf{k W})\end{array}$ & $\begin{array}{l}\text { 1/4 Load } \\
\text { (gal/hr) }\end{array}$ & $\begin{array}{l}\text { 1/2 Load } \\
\text { (gal/hr) }\end{array}$ & $\begin{array}{l}\text { 3/4 Load } \\
\text { (gal/hr) }\end{array}$ & $\begin{array}{l}\text { Full Load } \\
\text { (gal/hr) }\end{array}$ \\
\hline 20 & 0.6 & 0.9 & 1.3 & 1.6 \\
40 & 1.6 & 2.3 & 3.2 & 4 \\
60 & 1.8 & 2.9 & 3.8 & 4.8 \\
75 & 2.4 & 3.4 & 4.6 & 6.1 \\
100 & 2.6 & 4.1 & 5.8 & 7.4 \\
125 & 3.1 & 5 & 7.1 & 9.1 \\
135 & 3.3 & 5.4 & 7.6 & 9.8 \\
160 & 3.6 & 5.9 & & \\
\hline
\end{tabular}

\subsection{Co-located Banks with the Designed Power Pooling Scheme}

With the designed power-pooling scheme, the three scheduled generators will be operating in their full capacity. From Table 7, the gallon of fuel consumed per hour by each of the $160 \mathrm{~kW}$ rated generator is gotten to be $10.9 \mathrm{gal} / \mathrm{hr}$.

So, each of these three synchronized generators will consume;

$10.9 \mathrm{gal} / \mathrm{hr} \times 10=109$ gallons of diesel every day.

Therefore, the three generators will consume about 327 gallons per day. With the above calculations, the number of gallons of diesel required to serve the entire five banks network has been reduced from 420 gallons to 327 gallons. This gives diesel savings of 93 gallons per day.

A gallon $=4.5$ litres, 93 gallons will give 418.5 Litres daily.

\subsection{Cost of Generator Maintenance When There Is No Pooling Scheme}

The maintenance cost of a diesel generator is a function of output capacity of the generators and the numbers of hour in operation.

The diesel generator maintenance cost as a function of the output power generation can be estimated by the following model [20].

$$
C M_{D G i}=\sum_{I=1}^{N} K M_{D G i} P_{D G i}(t)
$$

where $C M_{D G i}$ is the maintenace cost of the ith diesel generator

$K M_{D G i}\left(\frac{\text { naira }}{k W h}\right)$ is the coef ficient of the maintenace cost of the ith generator

$P_{D G i}(t)$ is the output capacity of the generator in $(k W)$

The maintenance schedule recommended by the manufacturers of these generators is that it should be maintained after 1000 hours in operation.

From the information supplied by one of the plant operators; it takes N45,000 to maintain each of the $160 \mathrm{~kW}$ for every 1000 running hours. From this information $K M_{D G i}$ can be calculated as:

$$
K M_{D G i}=\frac{45000}{160 \times 1000}=0.28125 \mathrm{Naira} / \mathrm{kW}
$$

Therefore, the total maintenance cost for independent generator operation of the five banks without pooling scheme gives;

$45,000 \times 5$ (the number of independent generators) $=$ $\mathrm{N} 225,000$ for every 1000 hours in operation

\subsection{Cost of Generator Maintenance with Designed Power Pooling Scheme}

Applying equation (3.27) and all other stated diesel maintenance function as stated in subsection $\mathrm{C}$, the maintenance cost for the scheduled and synchronized three generators is calculated as: $45,000 \times 3$ (the number of synchronized generators) $=$ N135,000 for every 1000 hours in operation. 
So, from the calculated costs, it is observed that about $\mathrm{N} 90,000$ is maintenance cost difference between the two scenarios when there is power pooling scheme and when there is not.

\subsection{Cost of Greenhouse Gas Emission (Carbon Footprint) of the Generators}

The total costs for greenhouse gases emissions majorly carbon dioxide (CO2), carbon II oxide (CO), sulphur dioxide (SO2) and nitrogen oxide for diesel generators is given as:

$$
E(t)=\sum_{j=1}^{k} \sum_{i=1}^{N} E_{j, i} C_{j} P_{D G i}(t)
$$

Where $C_{j}(\mathrm{Naira} / \mathrm{kg})$ is the price for emission of $\mathrm{jth}$ greenhouse gas and $E_{j, i}(\mathrm{~kg} / \mathrm{kWh})$ is the emission rate of the $\mathrm{j}$ th greenhouse gas from ith diesel generator. $\mathrm{N}$ and $\mathrm{K}$ are the total number of diesel generators and greenhouse gases respectively [9].

From equation (9) the cost of greenhouse gas emission has direct relationship with the number of generators in operation. So, when the power pool scheme is employed in the co-located bank network the number of generators will be reduce to three units $(40 \%)$, so also the cost of greenhouse emission.

\section{Results}

\subsection{Load and Generator Data Results for the Selected Banks}

The plotted pie chart in Figure 6 is the result obtained from connected loads compared to available generator capacity in Table 1.

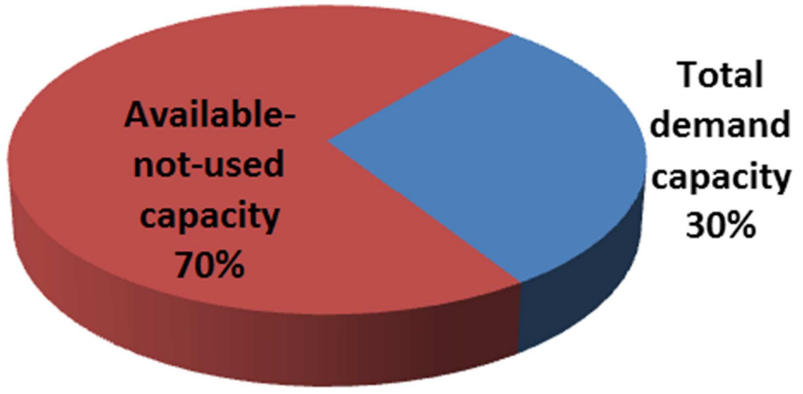

Figure 6. Pie Chart of the available and demand capacity.

Figure 7 is the daily load curves plotted from the load profile table in Table 2.

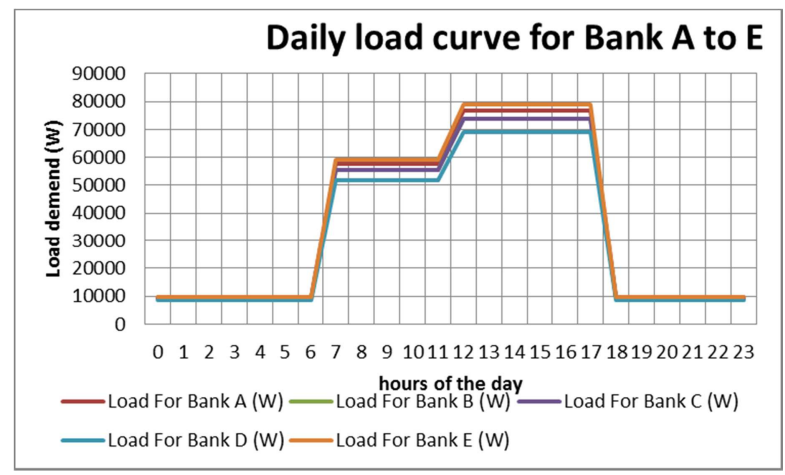

Figure 7. Daily load curves of the five selected banks.

\subsection{Load Flow ANalysis for the Interconnected Circuit Network}

From the MATLAB simulation of the interconnected co-located network, the following results were obtained as shown in Table 8.

Table 8. MATLAB Load flow Simulation result of the power pool interconnected network.

\begin{tabular}{|c|c|c|c|c|c|c|c|}
\hline \multirow{2}{*}{ Bus No } & \multirow{2}{*}{ Voltage mag. (pu) } & \multirow{2}{*}{ Angle mismatch in degree } & \multicolumn{2}{|l|}{ Load } & \multicolumn{2}{|c|}{ Generation } & \multirow{2}{*}{$\begin{array}{l}\text { Injected } \\
\text { MVAr } \\
\end{array}$} \\
\hline & & & MW & MVAr & MW & MVAr & \\
\hline 1 & 1.000 & 0.000 & 0.092 & 0.000 & 0.149 & 0.070 & 0.000 \\
\hline 2 & 0.997 & 0.003 & 0.092 & 0.069 & 0.000 & 0.000 & 0.000 \\
\hline 3 & 1.000 & 0.024 & 0.096 & 0.000 & 0.160 & 0.078 & 0.000 \\
\hline 4 & 0.998 & 0.060 & 0.099 & 0.074 & 0.000 & 0.000 & 0.000 \\
\hline 5 & 1.000 & 0.086 & 0.086 & 0.000 & 0.160 & -0.005 & 0.000 \\
\hline Total & & & 0.466 & 0.143 & 0.466 & 0.144 & 0.000 \\
\hline
\end{tabular}

\subsection{Generator Operating Schedule Results}

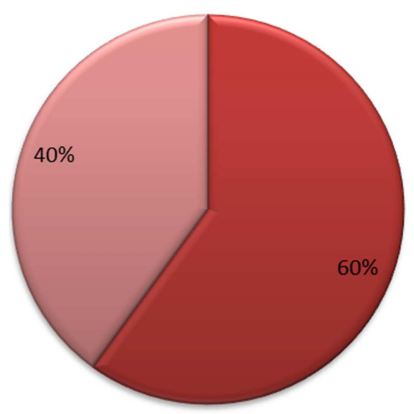

Total man-hour with pooling scheme (hours)

$\square$ Saved man-hour (hours)

From the operational generator schedule in Table 5 and Table 6 the plant operators will only be on duty when their bank is supplying power to the pool, therefore out of the 10 days each plant operator will only work for 6 days.

The pie chart plot in Figure 8 shows the total man-hour saved when the pool scheme is employed.

\subsection{Results from the Cost Benefit Analysis of the Designed Power Pool}

The bar chart plots in Figure 9 shows the cost savings when the designed power pool is implemented.

Figure 8. Pie chart for operational man-hour of plant operators. 


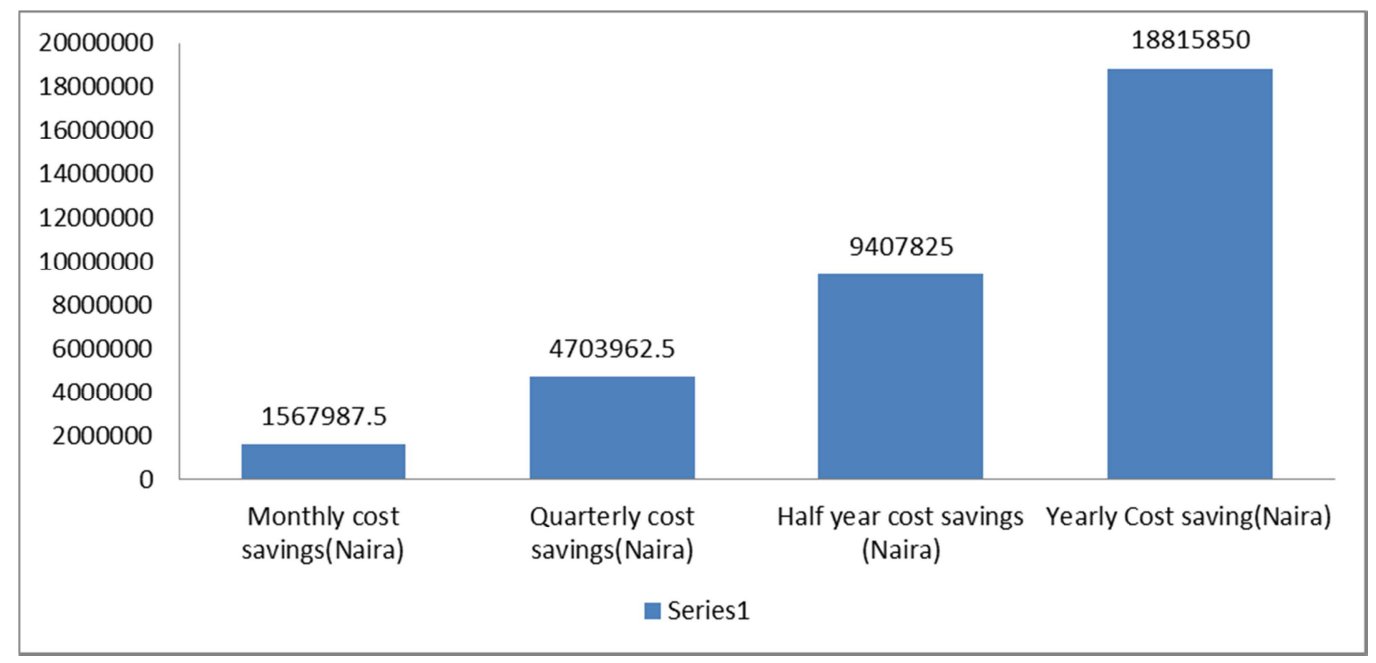

Figure 9. The bar chart plot of the cost savings.

\section{Conclusion}

The design of a power pool scheme for demand-side management of co-located banks in Owerri metropolis, Nigeria was carried successfully. The cooperating banks' generators and load buses were arranged in the power pool arrangement to form a localized distribution network and Newton-Raphson's method of load flow analysis was used to analyze the formed network. From load analysis carried out, the load flow results showed that this design can be practically implemented.

The generators were scheduled appropriately, and a cooperative pooling model was developed such that only the exact generating capacities were deployed. With the generator scheduling, it was shown that the total man-hour of the plant operators was reduced by $40 \%$. Scheduling the generators based on demanded load leads to increase of the numbers of available standby generators to be deployed during emergencies, thereby making the system more robust and reliable.

The cost benefit analysis showed that there will be a whopping cost savings of about N18,815,850 (eighteen million eight hundred and fifteen thousand eight hundred and fifty naira per year) when the power pool is implemented.

Generally, this research work showed that the power pooling network is cost efficient, more reliable with less noise pollution and carbon footprint since the individual 5 generator units have been reduced to 3 cooperating generator units and the 7 remaining units are there as redundancy.

This research work if implemented will solve the local problem of individual electricity generation cost, which has led to the flight of many international firms. It will also reduce the cost of running a business, and the carbon footprints released to the atmosphere.

A power pool scheme model is recommended for all the co-located firms with same line of business operation. It has been noticed that in major cities in Nigeria like, Enugu, Abuja, Owerri, Onitsha and Aba that commercial banks are majorly cited within a particular zone, so this work is also recommended in this various city.

Further work is also recommended for heterogeneous load system; where different electricity consumers are closely located like the market and residential areas.

\section{References}

[1] H. Saadat "Power System Analysis" WCB/McGraw-Hill Publishers USA, 1999.

[2] I. Drovtar, P. Uuemaa, A. Rosin, J. Kilter, and J. Valtin, "Using demand side management in energy-intensive industries for providing balancing power - The Estonian case study," IEEE Power Energy Soc. Gen. Meet., pp. 1-5, 2013.

[3] N. Farzam and L. YunWei, "Overview of Power Management Strategies of Hybrid," IEEE Trans. Power Electron., vol. 30 No. 12, pp. 7072-7089, 2015.

[4] N. E. S. O. Reports, "Daily Operational Reports," 2018. [Online]. Available: www.nsong.org. [Accessed: 12-Jan-2019].

[5] World Bank, Doing Business 2015: Going Beyond Efficiency. 2015.

[6] M. R. Quality, Doing Business 2016: Measuring Regulatory Quality and Efficiency. 2016.

[7] B. Malam, "Electricity Consumption and Nigeria's Economic Growth : Causality Test Based on VECM Framework," no. June, 2018.

[8] T. S. Oladimeji and O. B. Akinwale, "Community-Based Power Generation : A Viable Option for Nigeria. " $4{ }^{\text {th }}$ Annual NAEE/IAEE International Conference, Abuja, Nigeria, 29 April, 2011.

[9] M. R. Narimani, P. J. Nauert, J. Y. Joo, and M. L. Crow, "Reliability assesment of power system at the presence of demand side management," 2016 IEEE Power Energy Conf. Illinois, PECI 2016, 2016.

[10] A. Barbato and A. Capone, "Optimization models and methods for demand-side management of residential users: A survey," Energies, vol. 7, no. 9, pp. 5787-5824, 2014. 
[11] C. Shang, D. Srinivasan, and T. Reindl, "Joint generation and multiple demand scheduling in off-grid buildings," 2015 IEEE Int. Conf. Build. Energy Effic. Sustain. Technol. ICBEST 2015, September, pp. 50-55, 2015.

[12] Economic Commission for Africa, "Assessment of Power Pooling Arrangements in Africa."October 2004 [online]. Available: http://uneca.org[Accessed 12-Jan-2019].

[13] N. K. Paliwal, R. Mohanani, N. K. Singh, and A. K. Singh, "Demand side energy management in hybrid microgrid system using heuristic techniques," Proc. IEEE Int. Conf. Ind. Technol., vol. 2016-May, 2016.

[14] F. R. Volume, "Update of the ECOWAS Revised Master Plan for the Generation and Transmission of Electircal Energy Final Report Volume 4 : Executive summary,” vol. 4, October, 2011.

[15] R. C. Schaefer, "The Art of Generator Synchronizing" IEEE Trans. on Industry Applications 53. 1-1, 10.1109/TIA.2016.2602215, pp. 1-8, january 2016.

[16] A. P. Generation, "Parallel Generators and Synchronization,
Generator Power System Design. " [online]. Available: www.aksapowergen.com [Accessed 12-Jan-2019].

[17] U. Amin, G. Ahmad, S. Zahoor, and F. Durrani, "Implementation of Parallel Synchronization Method of Generators for Power \&amp; Cost Saving in University of Gujrat," Energy Power Eng., vol. 06, no. 10, pp. 317-332, 2014.

[18] E. hub projects and Tutorial, "Synchronization of generators." [Online]. Available: http://www.electronicshub.org/synchronization-of-generators. [Accessed: 23-May-2018].

[19] S. Benhamed, H. Ibrahim, and K. Belmokhtar, "Dynamic Modeling of Diesel Generator Based on Electrical and Mechanical Aspects," October 2017.

[20] M. K. Al-Saadi, P. C. K. Luk, and W. Fei, "Impact of unit commitment on the optimal operation of hybrid microgrids," 2016 UKACC Int. Conf. Control. UKACC Control 2016, no. 2, 2016. 